Article

\title{
Cataloguing of the Defects Existing in Aluminium Window Frames and Their Recurrence According to Pluvio-Climatic Zones
}

\author{
Manuel J. Carretero-Ayuso ${ }^{1}$, Carlos E. Rodríguez-Jiménez ${ }^{2, *}$, , David Bienvenido-Huertas ${ }^{2}$ (D) \\ and Juan Moyano ${ }^{3}$ (1) \\ 1 Musaat Foundation and Polytechnic College, University of Extremadura, 10004 Cáceres, Spain; \\ carreteroayuso@yahoo.es \\ 2 Department of Building Construction II, University of Seville, 41012 Seville, Spain; jbienvenido@us.es \\ 3 Department of Graphical Expression and Building Engineering, University of Seville, 41012 Seville, Spain; \\ jmoyano@us.es \\ * Correspondence: ceugenio@us.es
}

Received: 5 August 2020; Accepted: 6 September 2020; Published: 9 September 2020

\begin{abstract}
The sustainability of building envelopes is affected by its windows, since these establish the connection/separation between the indoor rooms and the external environment. They can also lead to problems if they do not offer sufficient protection against external agents. The data source in this research is unprecedented, as it is based on records of court sentences. There is a significant number of cases (1615), which provides high representativeness for the functional reality of windows. The methodology that was developed classifies the defects and the causes that were found, also analysing correspondence with their recurrence according to aspects of climatological location. In the results, the cases pertaining to water infiltration, air permeability and humidity by condensation are highlighted. This study provides a vision that categorizes problems related to aluminium windows that may be useful for future interventions by agents participating in the construction process.
\end{abstract}

Keywords: air permeability; watertightness; airtightness; infiltration; aluminium window frames

\section{Introduction}

Windows are indispensable construction units for building facades, given their implications for basic aspects related to habitability and comfort such as watertightness [1], air permeability [2], lighting [3], etc. At the same time, these openings interrupt the continuity of external walls and amount to numerous singularities in the construction solution that still need to meet all requirements of the envelope, without decreasing the performance of the whole. In fact, when characterising windows, one must note both their own elements (the frame and the glazing) and all the perimeter elements that are part of the opening (external windowsill, lintels, jambs and blinds, as well as the assembly and sealants) that share the same functions. As such, windows constitute one of the most problematic elements in the study of the envelopes of buildings, these being determinant for attaining suitable parameters for their performance [4].

In this way, the interrelation between the sustainability of the property and that of its windows is quite significant [5]. Windows exert an influence on basic aspects of building functionality, both at the level of internal comfort and with regard to maintenance, construction quality and repairs throughout buildings' service lives. This is shown by the direct effects that dysfunctions related to windows have on the increase in the work and maintenance costs of the building-all key factors in their sustainability [6,7]. Equally, in the construction phase for buildings, windows are decisive for both quality and costs, featuring among some of the common non-conformities that arise during 
execution, and lead to significant deviations from the initial budgets for the works [8]. Windows are also usually a part of renovations that take place during the service lives of buildings and are key to evaluating the perception of the quality of houses, as can be observed in the efficiency indicators established subsequent to repair and rehabilitation works [9].

In the studies on the openings of windows, there are numerous lines of enquiry, with a recent focus on energy efficiency, which constitutes one of the critical points in the analysis that was carried out. As for energy savings, windows have different considerations. On the one hand, when aspects related to the air permeability of the thermal envelope are addressed, these are responsible for most of the volume infiltrated through the envelope [10,11]. On the other hand, one must remember that the transmittance of windows is one of the main points of the facades through which internal heat and cold are lost. This is the case because their values are usually clearly lower toward the opaque parts-due to the characteristic values of the materials usually employed in the frames and in the glazing [12,13], as well as to the probability of the appearance of thermal bridges in the most common construction solutions [14]. In this line of research, there are numerous publications that examine the insulation provided by windows, its impact on building energy demands and interventions for improving it $[15,16]$. From this energy perspective, one should also note the effect of solar radiation entering the building through the glazing of windows, the consequences of which are not always easy to mitigate [17].

Construction aspects are also relevant to the study of windows, since these influence numerous building defects. The problems related to humidity make up a large portion of the damage related to traditional facades [18]. Based on this assumption, the existence of numerous joints and operable parts leads to windows and the contours of their respective openings being especially vulnerable to rainwater infiltration [19]. Equally, the flows of temperature and moist air that go through windows are reflected in the appearance of humidity by condensation [20]. Additionally, despite its lesser impact, one must also point to the roles played by windows and their perimeter elements in the causes of some problems related to fissurations and to the stability walls, especially those made with bricks [21].

Given the amplitude of this set of factors related to defects in windows and their environment, inspection and diagnosis activities that can effectively detect problems and dysfunctions in these construction elements become very important. In the last few years, there has been, in this field, an important development in the methods used for the testing of windows and other elements of the building envelope, largely due to the needs of energy evaluations for buildings [22]. In this way, permeability measurement techniques such as the test blower door [23,24], thermometric tests for the measurement of the transmittance [25], infrared thermography [26] and tests of watertightness against the effects of wind-driven rain [27], among others, are increasingly present (both in the scientific literature and in their spread in the industry).

As a result, the knowledge as to construction defects in windows shows a panorama with multiple variables [28]. In the face of this situation, it is especially useful to have carefully categorised databases for a clear definition of critical points to be able to avoid the repetition of problems in future construction interventions, actively contributing to their sustainability. It is not very common to find publications that incorporate any type of cataloguing of construction problems. Nevertheless, certain examples are found to be focused on the typologies of defects related to the building in general [29] and on the reasons behind repairs and renovations [30]. Of particular interest to this research is the work focusing on window frames, including studies on the influence of frame components [31,32], on degradation [33] and on modelling the inspection for window defects [34] or on predicting their service lives [35,36].

The current study provides a novel analysis of defects related to windows (as well as their causes), since it was carried out on a large database of judicial complaints filed by users. It is thus intended to provide a classification and grading of defects that were actually complained about by building users, as well as evaluating their recurrence according to climatic location. In this regard, the influence of rainfall, climate and latitude on the appearance of defects was also examined. 


\section{Methodology}

\subsection{Scope of Study}

The data for this research were obtained from the records of complaints for damages of the civil responsibility insurance company of building engineers in Spain [37]. Each record originated from the observation of a construction defect between the years 2008 and 2017 [38] that was subsequently the target of a judicial complaint and was definitively resolved before its inclusion in this paper.

These records (that were handled directly by the authors) contain not only data on the contract between the insurance company and the insured party but also the sentences of the courts of law, according to the complaints filed by the users of the buildings in which the construction defects appeared.

These sentences, issued after the verification by the courts of law that the defects in question were indeed present, detailed the characteristics of the defects, indicating that the problems in question should be resolved. The initial sentences could be appealed to higher courts a number of times until they were no longer appealable and were considered final. That is the point at which the authors proceeded with including the data as part of this research. A copy of all those judicial documents is held by the insurance company of the participating building engineers. It was necessary, as such, to review thousands of pages in these records to extract the technical data and separate them from administrative or contractual information.

No precedents were found for research carried out by other authors on window defects based on this type of database, nor was a relevant data set with such a large number of cases (1615) found.

\subsection{Characterisation}

The parameters characterised in the research were the following- "effects" (d) and "originating cause" (OC) - both for windows (W), as the construction unit under study. Windows are classified into two types: normal windows (NW) and bay windows (BW); all of the windows had aluminium frames.

Table 1 shows the different types of defects and originating causes, as well as the codes assigned to them (this is the material that is most predominant in Spain, whereas other materials, such as wood, are seldom used in window frames).

Table 1. Types of defects and originating causes that were analysed.

\begin{tabular}{ccc}
\hline Parameter & Concept & Code \\
\hline \multirow{2}{*}{ Defects } & Water infiltration & dWI \\
& Air permeability & dAP \\
& Humidity by condensation & dHC \\
& Oxidation or corrosion & dOC \\
\hline Originating causes & Absence/deficiency of sealant & ocAS \\
& Inadequate construction material and/or placement & ocIC \\
& Existence of thermal bridges & ocTB \\
& Incorrect assembly process & ocIA \\
\hline
\end{tabular}

Likewise, the 'construction typology' of the windows with defects was also studied, being divided into 'flats', 'houses' and 'other buildings'. Below are shown some photographic examples of some of the defects (Figure 1). 


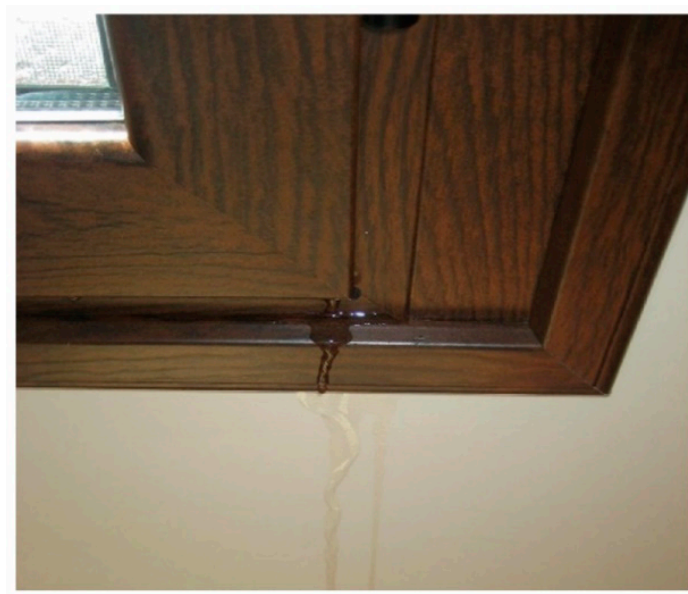

Infiltration of rainwater through a window

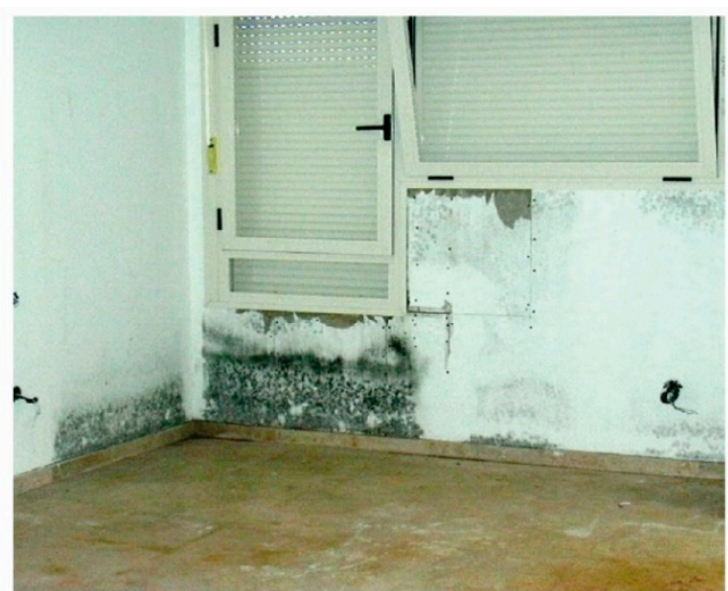

Humidities on the inside of a wall and two windows

Figure 1. Photographic examples of two types of defects studied.

\subsection{Factors of Study}

In addition to the parameters indicated above, in this research were also used other concepts that enabled ascribing each one of the defects to a climatological factor. There were three factors, indicated in Table 2. This table also indicates the categories into which each factor is broken down.

Table 2. Types of factors and their categories, as included in the research.

\begin{tabular}{llcccc}
\hline \multicolumn{2}{c}{ Factor } & \multicolumn{3}{c}{ Categories } \\
\hline Factor 1: & Rainfall & High & Medium & Low & - \\
Factor 2: & Climate & Oceanic & Continental & Mediterranean & Subtropical \\
Factor 3: & Latitude & North & Central & South & - \\
\hline
\end{tabular}

The information related to the factors established for each geographical area of the territory in question (Spain) is referred to in this study as 'location strips'. Their classification was carried out based on the indications of the Spanish Meteorology Agency [39]:

- Rainfall. It consists of three categories: 'High' (>700 mm/m²), 'Medium' (between 450 and $700 \mathrm{~mm} / \mathrm{m}^{2}$ ) and 'Low' $\left(\leq 450 \mathrm{~mm} / \mathrm{m}^{2}\right)$, according to the available meteorological data.

- Climate. It is made up of four categories: 'Oceanic', 'Continental', 'Mediterranean' and 'Subtropical'. Small sub-areas, with a reduced extension, were not considered in this factor.

- Latitude. It consists of three categories: 'North', 'Central' and 'South'. It corresponds to the geographical areas according to their situation within Spain.

Using said factors, a percentage study was carried out for the recurrence of all defects, applying each factor individually, combining two at a time, and combining the three factors together. In this way, one obtains the 'percentage of number of cases' (\%NC), which corresponds to the different cases (location strips) when applying the categories into which Factors 1, 2 and 3 are sub-divided.

Subsequently, using these \%NC values and simultaneously applying the three factors (a closer approximation of reality), the percentages are sorted to subsequently establish the 'ranks of concentration of defects'.

In order to homogenise the values obtained, the following was carried out:

- The percentages of the 'location strips' that were closer are added up to one another and sorted from largest to smallest, the value thus obtained being referred to as 'total \% $\mathrm{NC}^{\prime}$.

- The aforementioned value was divided by the number of homes in Spain [40] for that set of location strips, obtaining an dimensionless value that could be compared (relative frequency). 
- With the objective of better handling and visualising these last values, the relative frequencies were divided by the largest value, thus obtaining a 'normalised relative frequency' for each pluvio-climatic zone.

The eleven results by 'location strips' and by three factors were characterised to obtain the 'ranks of concentration of defects' according to the percentages obtained. From the values of these ranks, 'zones pluvio-climatic' were configured in such a way that all those eleven combinations were simplified into just three zones (ZONE A, ZONE B and ZONE C).

\section{Results}

\subsection{Results by Type of Element and Defect}

Figure 2a shows the number of cases by type of element. Normal windows amount to $95 \%$ of the total ( $\mathrm{NW}=1538$ cases), while bay windows constitute the remaining $5 \%$ (BW $=77$ cases). In turn, Figure $2 \mathrm{~b}$ represents the percentage distribution according to the types of defects, it being shown that 6 out of every 10 cases belong to 'water infiltrations' $(\mathrm{dWI}=60.8 \%)$. The following defects-'air permeability' ( $\mathrm{dAP}$ ) and 'humidities by condensation' (dHC) - are practically the same.

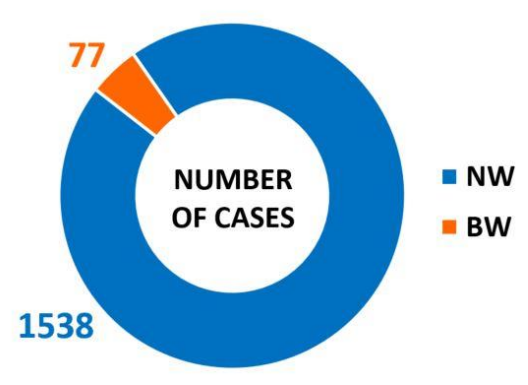

(a)

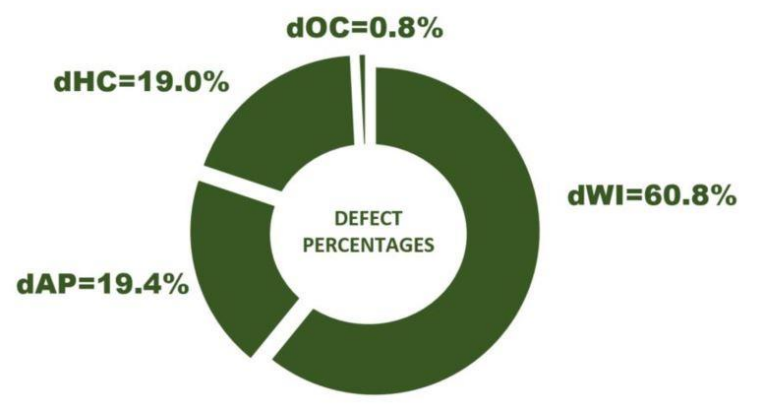

(b)

Figure 2. Numbers of cases in the research (a) and percentages by types of defects (b).

If we break down the number of cases for each type of defect and according to the element in which it occurs (normal window or bay window), we obtain the values that are shown in Figure 3.

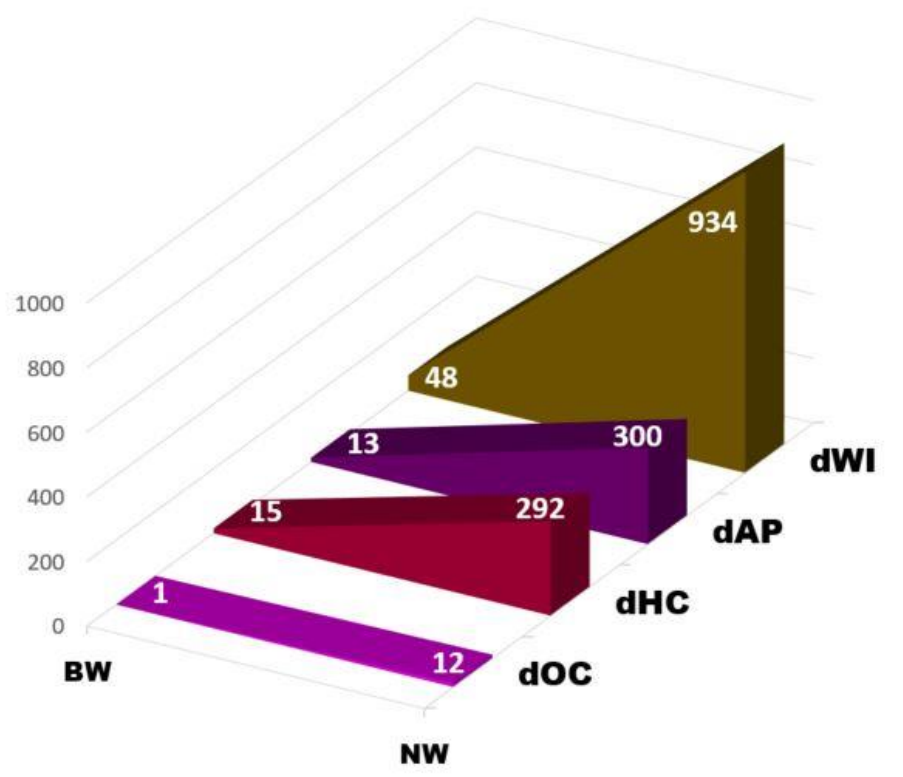

Figure 3. Number of cases by type of defect and by type of element. 
Based on Figures 2 and 3, it is evident that problems related to the performance of windows in terms of hermeticity (in terms of permeability to air as well as water) represent nearly the totality of the impact on building users. This implies that the construction configuration and the commissioning of windows must mainly satisfy the requirements on watertightness (absence of infiltrations) and air permeability.

\subsection{Results by Type of Originating Cause}

As indicated in the methodology section, four different types of originating causes were found in this research. It can be noted that the 'absence/deficiency of sealant' occurs practically $2 / 3$ of the time (ocAS $=66.4 \%$ ). The second position (ocIC $=$ inadequate construction material and/or placement) and the third position (ocTB = existence of thermal bridges) have quite similar values, differing by less than one percentage point.

Consequently, with the distribution of the originating causes shown in Figure 4, one can observe a majority of issues pertaining to sealing and to the placement during construction. These aspects are directly related to water infiltration and air permeability ( $\mathrm{dWI}$ and $\mathrm{dAP}$ ). Complaints related to thermal parameters (ocTB and ocIA) appear to be far less relevant.

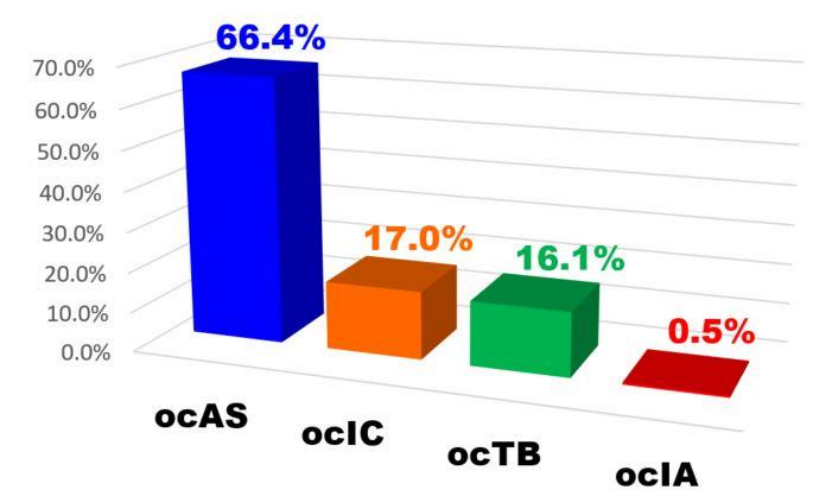

Figure 4. Percentage of recurrence according to the type of originating cause.

\subsection{Determination of the Pathology Trinomial Sets}

The term 'pathology trinomial set' will be used to refer to construction interrelations that lead a certain type of originating cause to produce a type of defect in one of the two types of windows studied. The data analysed yield 16 different combinations.

Figure 5 shows the number of cases for each one of the 16 pathology trinomial sets found. For a simpler conceptual association, the colours employed for the originating causes are the same as those employed in Figure 4, and the identifying colours for the defects are those used in Figure 3. In addition, Figure 5 indicates the number of cases for each one of the types of defects and originating causes so that they can be evaluated as part of the whole set of the results found.

The most frequent trinomial set is 'absence/deficiency of sealant' that leads to 'water infiltrations' in 'normal windows' (ocAS-dWI-NW = 779). It is followed in second place by the 'existence of thermal bridges' that leads to 'humidity by condensation' in 'normal windows' (ocTB-dHC-NW = 247). In third place is the 'absence/deficiency of sealant' that leads to 'air permeability' in 'normal windows' (ocAS-dAP-NW = 246). The fourth position is held by 'inadequate construction material and/or placement' that leads to 'water infiltrations' in 'normal windows' (ocIC-dWI-NW $=155$ ).

The sum of cases of these first four pathology trinomial sets (from among the 16 sets) equals 1427 cases, or $93 \%$ of all the cases. As such, there is a Pareto relation of $25-93 ; 25 \%$ of the pathology trinomial sets lead to $93 \%$ of the cases researched.

Some other aspects can also be highlighted: defect dOC is only originated by cause ocIC, cause ocTB only leads to defect $\mathrm{AHC}$, cause ocIA only leads to defect dAP, cause ocAS leads to two defects, and cause ocIC leads to all the types of existing defects. 
These pathology trinomial sets confirm that, to reduce most of the problems found and to reduce most of the problems found during the service life, windows should be constructed with the utmost care for their hermeticity (air permeability and watertightness). It is highly recommended to carry out verifications in situ ofn these aspects before the commissioning of the building.

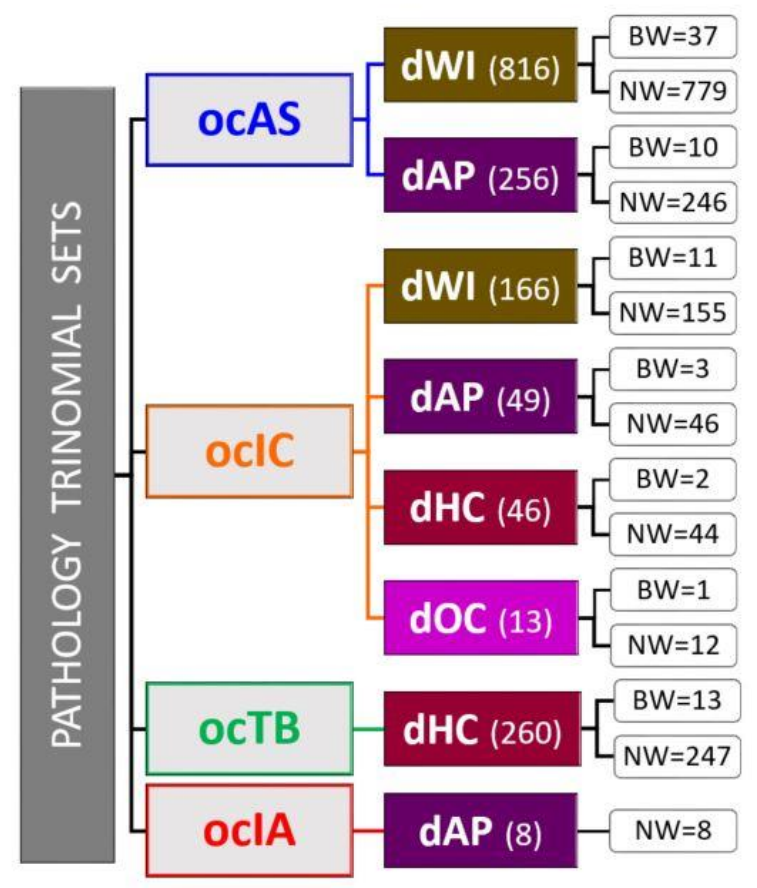

Figure 5. Number of cases according to the type of pathology trinomial set found.

\subsection{Results by Construction Typologies}

As indicated, during the process of data collection, the typology construction wherein each of the defects occurred was noted. The higher percentages were found in 'flats' (63.03\%). See Figure 6.

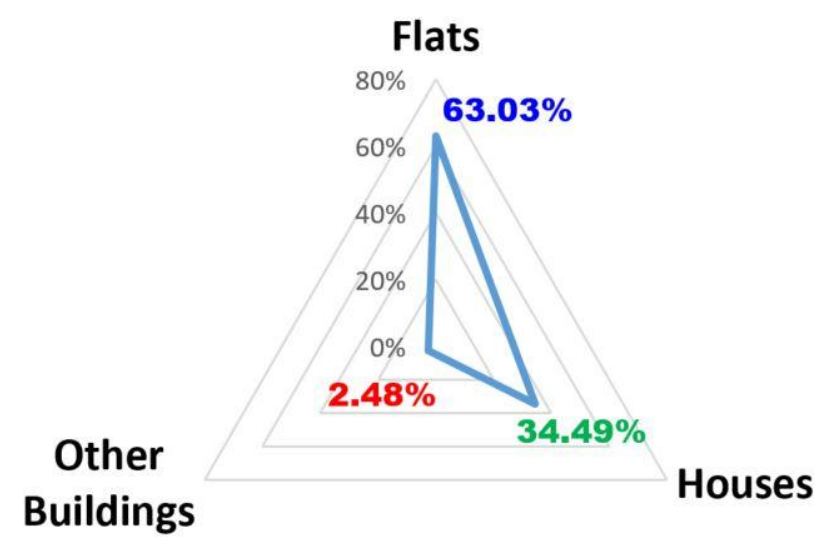

Figure 6. Percentage of defects according to the construction type.

From this distribution, it can be deduced that the greater height of multi-storey buildings, which increases their exposure to weather, may explain the frequency of complaints in this type of building.

\subsection{Pluvio-Climatic Study of Defects}

Given that the defects collected in the database are mainly related to environmental parameters (humidity, air infiltration, etc.), their relationship with the factors of the different climatic areas will be of interest. 
The analysis that is carried out in this section explores the recurrence of these problems according to the pluvio-climatic location of the cases in a way that establishes a quantitative association between defects and weather conditions.

\subsubsection{Determination of the Location Strips}

Table 2 establishes the three main factors of the environment: rainfall, climate and latitude, as well as their respective categories. Their details are shown in Table 3, which contains the different combinations of these categories, resulting in 'location strips'.

Table 3. Percentages of recurrence of the defects according to each of the factors analysed.

\begin{tabular}{|c|c|c|c|c|}
\hline \multicolumn{2}{|c|}{ Factor } & Location Strip & $\% \mathrm{NC}$ & $\%$ Total \\
\hline \multirow{3}{*}{ Single Factor } & Rainfall & $\begin{array}{l}\text { High } \\
\text { Medium } \\
\text { Low }\end{array}$ & $\begin{array}{l}28.05 \% \\
54.86 \% \\
17.09 \%\end{array}$ & Factor 1 \\
\hline & Climate & $\begin{array}{c}\text { Oceanic } \\
\text { Continental } \\
\text { Mediterranean } \\
\text { Subtropical }\end{array}$ & $\begin{array}{c}28.92 \% \\
30.46 \% \\
37.15 \% \\
3.47 \%\end{array}$ & Factor 2 \\
\hline & Latitude & $\begin{array}{l}\text { North } \\
\text { Central } \\
\text { South }\end{array}$ & $\begin{array}{l}51.27 \% \\
29.47 \% \\
19.26 \%\end{array}$ & Factor 3 \\
\hline \multirow{3}{*}{$\begin{array}{c}2 \text { Factor } \\
\text { Combination }\end{array}$} & $\begin{array}{l}\text { Rainfall and } \\
\text { Climate }\end{array}$ & $\begin{array}{c}\text { High-Oceanic } \\
\text { Medium-Continental } \\
\text { Medium-Mediterranean } \\
\text { Low-Continental } \\
\text { Low-Mediterranean } \\
\text { Low-Subtropical }\end{array}$ & $\begin{array}{c}28.92 \% \\
22.72 \% \\
31.27 \% \\
7.74 \% \\
5.88 \% \\
3.47 \%\end{array}$ & $\begin{array}{c}\text { Factor } 1 \\
+ \\
\text { Factor } 2\end{array}$ \\
\hline & $\begin{array}{l}\text { Rainfall and } \\
\text { Latitude }\end{array}$ & $\begin{array}{l}\text { High-North } \\
\text { Medium-North } \\
\text { Medium-Central } \\
\text { Medium-South } \\
\text { Low-North } \\
\text { Low-Central } \\
\text { Low-South }\end{array}$ & $\begin{array}{c}28.92 \% \\
19.20 \% \\
24.89 \% \\
9.90 \% \\
3.16 \% \\
4.58 \% \\
9.35 \%\end{array}$ & $\begin{array}{c}\text { Factor } 1 \\
+ \\
\text { Factor } 3\end{array}$ \\
\hline & $\begin{array}{l}\text { Climate and } \\
\text { Latitude }\end{array}$ & $\begin{array}{c}\text { Oceanic-North } \\
\text { Continental-North } \\
\text { Continental-Central } \\
\text { Continental-South } \\
\text { Mediterranean-North } \\
\text { Mediterranean-Central } \\
\text { Mediterranean-South } \\
\text { Subtropical-South }\end{array}$ & $\begin{array}{c}28.92 \% \\
10.40 \% \\
17.71 \% \\
2.35 \% \\
11.95 \% \\
11.76 \% \\
13.44 \% \\
3.47 \%\end{array}$ & $\begin{array}{c}\text { Factor } 2 \\
+ \\
\text { Factor } 3\end{array}$ \\
\hline \multirow{3}{*}{$\begin{array}{c}3 \text { Factor } \\
\text { Combination }\end{array}$} & High & High-Oceanic-North & $28.92 \%$ & \multirow{3}{*}{$\begin{array}{l}\text { Factor } 1 \\
\quad+ \\
\text { Factor } 2 \\
\quad+ \\
\text { Factor } 3\end{array}$} \\
\hline & Medium & $\begin{array}{l}\text { Medium-Continental-North } \\
\text { Medium-Continental-Central } \\
\text { Medium-Continental-South } \\
\text { Medium-Mediterranean-North } \\
\text { Medium-Mediterranean-Central } \\
\text { Medium-Mediterranean-South }\end{array}$ & $\begin{array}{c}7.25 \% \\
13.13 \% \\
2.35 \% \\
11.95 \% \\
11.76 \% \\
7.55 \%\end{array}$ & \\
\hline & Low & $\begin{array}{l}\text { Low-Continental-North } \\
\text { Low-Continental-Central } \\
\text { Low-Mediterranean-South } \\
\text { Low-Subtropical-South }\end{array}$ & $\begin{array}{l}3.16 \% \\
4.58 \% \\
5.88 \% \\
3.47 \%\end{array}$ & \\
\hline
\end{tabular}

$\% \mathrm{NC}=$ percentage of the number of cases.

As shown in the upper section of Table 3, the location strip with the highest percentage by rainfall is the 'medium' (54.86\%); by climate, it is the 'Mediterranean' (37.15\%), and by latitude, it is the 'north' $(51.27 \%)$. 
As indicated in the middle section of Table 3, it can be noted that there is one location strip that shows a higher result than the others by the percentage of recurrence of construction defects: 'medium-Mediterranean' (31.27\%). Following it, there is a triple tie between three location strips: 'high-oceanic', 'high-north' and 'oceanic-north'.

When combining Factors 1, 2 and 3 simultaneously (lower section of the same table), the location strips with the most cases are 'high-oceanic-north' (28.92\%) and 'medium-continental-central' (13.13\%).

\subsubsection{Determination of Zones by Ranks of Normalized Frequencies}

Table 4 establishes a quadrant in which 'pluvio-climatic zones' are defined according to the 'rank of concentration of defects'. Thus, according to the percentage of the number of cases $(\% \mathrm{NC})$, if it is greater than 15, one will be in ZONE A; if \%NC is between 7 and 15, one will be in ZONE B; and if $\% \mathrm{NC}$ is less than or equal to 7 , one will be in ZONE C.

Table 4. Classification by ranks of the pluvio-climatic zones sorted by intensity of recurrence.

\begin{tabular}{|c|c|c|c|c|c|c|c|}
\hline & $\begin{array}{c}\text { Location Strip } \\
\text { (Rainfall-Climate-Latitude) }\end{array}$ & $\% \mathrm{NC}$ & $\begin{array}{l}\text { Total } \\
\% \mathrm{NC}\end{array}$ & $\begin{array}{c}\text { Relative } \\
\text { Frequency } \\
\left(\times 10^{-5}\right)\end{array}$ & $\begin{array}{l}\text { Normalised } \\
\text { Relative } \\
\text { Frequency }\end{array}$ & $\begin{array}{l}\text { Pluvio- } \\
\text { Climatic } \\
\text { Zone }\end{array}$ & $\begin{array}{c}\text { Rank of } \\
\text { Concentration } \\
\text { of Defects }\end{array}$ \\
\hline 1 & High-Oceanic-North & $28.92 \%$ & $28.92 \%$ & 7.05 & 1.00 & A & $\% \mathrm{NC}>15$ \\
\hline 2 & Medium-Continental-Central & $13.13 \%$ & & & & & \\
\hline 3 & Medium-Mediterranean-North & $11.95 \%$ & & & & & \\
\hline 4 & Medium-Mediterranean-Central & $11.76 \%$ & $51.64 \%$ & 3.03 & 0.43 & B & $7<\% \mathrm{NC} \leq 15$ \\
\hline 5 & Medium-Mediterranean-South & $7.55 \%$ & & & & & \\
\hline 6 & Medium-Continental-North & $7.25 \%$ & & & & & \\
\hline 7 & Low-Mediterranean-South & $5.88 \%$ & & & & & \\
\hline 8 & Low-Continental-Central & $4.58 \%$ & & & & & \\
\hline 9 & Low-Subtropical-South & $3.47 \%$ & $19.44 \%$ & 2.51 & 0.36 & $\mathrm{C}$ & $\% \mathrm{NC} \leq 7$ \\
\hline 10 & Low-Continental-North & $3.16 \%$ & & & & & \\
\hline 11 & Medium-Continental-South & $2.35 \%$ & & & & & \\
\hline
\end{tabular}

The above-mentioned Table 4 also has an intermediate column (relative frequency) that includes the percentages of defects as a function of the numbers of homes in Spain in each of the location strips. Given that the relative frequencies were low, they were standardised: the highest relative frequency was assigned a value of $100 \%$. The remaining values referred to this normalised value (column named 'normalised relative frequency').

Based on Table 4, it can be noted that the regions of Spain situated to the North, with an oceanic climate and high rainfall, show higher standardised proportions of defects. In other words, windows located in buildings in these areas have a much greater risk of having defects that are complained about judicially. This is explained by the fact that these zones have a very moist environment and infiltration defects lead to frequent complaints. The exception is the last row of Table 4 ('Medium-Continental-South' strip) that possesses considerable rainfall and a low percentage. In this case, however, one must note the influence of the location to the South and the continental climate, which produces high temperatures, limiting the effect of humidity.

\subsubsection{Individual Analysis According to Each Factor and Type of Defect}

An analysis was carried to determine in which climate location strips each of the four types of defects found in windows occurs with a higher percentage of recurrence.

- Water infiltrations (dWI)

This defect occurs more with medium rainfall (54.28\%) than with high $(29.12 \%)$ or low rainfall $(16.60 \%)$. It was shown that there is a greater presence in the Mediterranean climate $(39.82 \%)$ than in the oceanic $(29.94 \%)$ or continental $(26.17 \%)$ climates. In addition, this defect occurs quite rarely in the subtropical climate (4.07\%). As for latitude, it is more common in the North $(48.37 \%)$ than in the Central part (28.41\%) or in the South $(23.22 \%)$. 
- $\quad$ Air permeability (dAP)

This type of defect occurs more with medium rainfall (61.98\%) than with high (23.96\%) or low rainfall (14.06\%). It was shown to occur with similar frequency in the Mediterranean $(37.08 \%)$ and continental climates (36.42\%), while in third place is the oceanic climate $(24.90 \%)$, and in last position is the subtropical climate $(1.60 \%)$. As for latitude, more than half of the time, dAP occurs in the North $(54.95 \%)$, occurring in the Central part almost one third of the time (31.31\%), while the South comes last (13.74\%).

- Humidity by condensation (dHC)

There is medium rainfall on approximately half of the occasions $(49.19 \%)$, followed by high $(28.34 \%)$ and low rainfall $(22.47 \%)$. Presence in the continental climate $(39.82 \%)$ was observed in the majority of cases, followed closely by the oceanic (29.32\%) and the Mediterranean $(28.01 \%)$ climates. As with previous defects, the subtropical climate was the least recurrent (3.58\%). As for latitude, the North clearly remains as the climate strip with the most cases $(56.68 \%)$, followed by the Central part (30.29\%) and the South (13.03\%).

- Oxidation or corrosion (dOC)

There are no cases of this type of defect with low rainfall, while more than one third of the time, it occurs with high rainfall $(38.46 \%)$, and nearly two thirds of the time, it occurs with medium rainfall $(61.54 \%)$. This defect also does not occur in the subtropical climate and has quite a low presence in the continental climate $(7.69 \%)$. It appears occasionally in the oceanic climate $(38.51 \%)$ and frequently in the Mediterranean climate (53.80\%). Lastly, this type of problem does not occur in the strips to the South of the country, and there is not a significant difference between the Central part (46.15\%) and the North (53.85\%).

The individual analysis by each factor and type of defect confirms the information presented in Table 4, in the sense that the most adverse climatological locations exhibited higher shares of defects. It can be highlighted that, considering only the phenomenon of rainfall, the places with medium rainfall have more cases than those with high rainfall. This must be explained by the higher performance of windows situated in areas where heavy rain leads to more careful construction practices.

\subsubsection{Breakdown of Defects in the Strips with Higher \%NC}

To have a more detailed perspective of how each of the types of defects were distributed in the most problematic location strips, Table 5 was produced. The criterion used was to select the four strips with $\% \mathrm{NC}>10 \%$.

Table 5. Number of cases according to each type of defect in the four most problematic location strips.

\begin{tabular}{lccccccc}
\hline & Location Strip & \%NC & dWI & dAP & dHC & dOC & Total of Cases \\
\hline 1 & High-Oceanic-North & $28.92 \%$ & 286 & 75 & 87 & 5 & 453 \\
2 & Medium-Continental-Central & $13.13 \%$ & 125 & 48 & 38 & 1 & 212 \\
3 & Medium-Mediterranean-North & $11.95 \%$ & 104 & 48 & 39 & 2 & 193 \\
4 & Medium-Mediterranean-Central & $11.76 \%$ & 123 & 38 & 24 & 5 & 190 \\
\hline
\end{tabular}

If said table is analysed, it can be seen that the distributions for each type of defect are quite similar with respect to the percentage of cases they represent in each of the location strips. Thus, dWI has a range of presence between $54 \%$ and $65 \%$ (with $60 \%$ as the average), $\mathrm{dAP}$ has a range of presence between $17 \%$ and $25 \%$ (with $21 \%$ as the average), $\mathrm{dHC}$ has a range of presence between $15 \%$ and $20 \%$ (with $17 \%$ as the average) and dOC has a range of presence between $0.5 \%$ and $3 \%$ (with $1 \%$ as the average). 


\section{Discussion}

\subsection{Reflections on the Database}

Based on Section 2 above, the method used in this research is not a 'survey' and is certainly not an 'experiment'. It is not a 'simulation', and it is also not a 'case study' (it does not focus on a specific case of a building or situation, or on a limited and unique area with previously selected characteristics). The analysis was carried out over the 'general census of cases' (taking into account and studying the global record of existing judicial records) for the entirety of a country, under the principles of generality and simultaneity.

As such, all the cases analysed correspond to the total set existing in Spain in the period of the study-in other words, $100 \%$ of all the emerging cases were collected herein (no case was left out). As such, they do not only constitute a more-or-less characteristic sample whose representativeness needs verifying; rather, they encompass the totality of all the defects found between the years 2008 and 2017 (there is no error or uncertainty, as it is not a partial sample). This constitutes another novel contribution of this research, given that it is generally not possible to collect the entirety of relevant data in a nation.

It should be pointed out that the set that was researched is quite homogeneous regarding building age. All the buildings, and all the windows analysed, had been built relatively recently. Spanish legislation envisions a three-year warranty period for this type of construction element, starting from the time the works are completed. As such, if any type of defect exists, owners should file judicial complaints in this period. This is why there is no dispersion or distortion of the data resulting from the possible deterioration of window frames caused by the passage of time.

As can be seen, the methodology did not include a number of other objectives that could also have been of interest but are out of the scope and fundamental ideas of this study. These could include trying to ascertain the possible responsibilities of the different participants. This aspect was explicitly left out of the permission given to the authors for accessing the data source, for which reason this aspect could not be assessed.

In future studies, it would be of interest to try to correlate defects with other climatological aspects. This analysis must be based on the exact location of each building-an aspect that was not possible to obtain in the data collection process, given the limitation that was imposed to maintain the confidentiality and protection of certain information. Should this sensitive information be accessible, one would correlate it with other external parameters not contained in the judicial process. All these parameters should be processed for each of the 1615 cases in question. This gives an idea of the difficulty of obtaining and quantifying all these variables.

\subsection{Several Considerations}

The knowledge of the most recurrent construction defects in different construction units is very important for trying to minimise them in subsequent technical interventions, be it during the design [41] or execution stages. There are also two additional advantages: possessing a good maintenance strategy during the service life and having a governmental public catalogue of construction defects. In order to achieve this goal, it would be necessary for a prior compilation to be produced of the most problematic construction points, with the highest numbers of cases, based on (for example) the actual/judicial records, as presented in this research. Furthermore, national regulations could include specific construction details on how these problematic points could be more effectively addressed. This aspect would enable collaboration to minimise future construction costs and improve maintenance during the use phase-a matter, indeed, that is being given significant attention by a number of publications [42-44]. 


\subsection{Teaching These Critical Aspects in Universities}

Students of architecture and engineering should have a greater understanding of building defects, so as to have knowledge on the main critical points and avoid making the same mistakes in the future (both in design and execution stages). This aspect is often not given sufficient attention in university degrees.

As a way of facilitating their understanding, and in order to deliver this knowledge in an eminently visual manner (given that the generation they are a part of often works with visual information), the authors have produced a number of infographics on different construction points (starting from the facade openings where windows are inserted). Based on their teaching experience, a number of encouraging results are being obtained. One example of these infographics is shown in Figure 7.
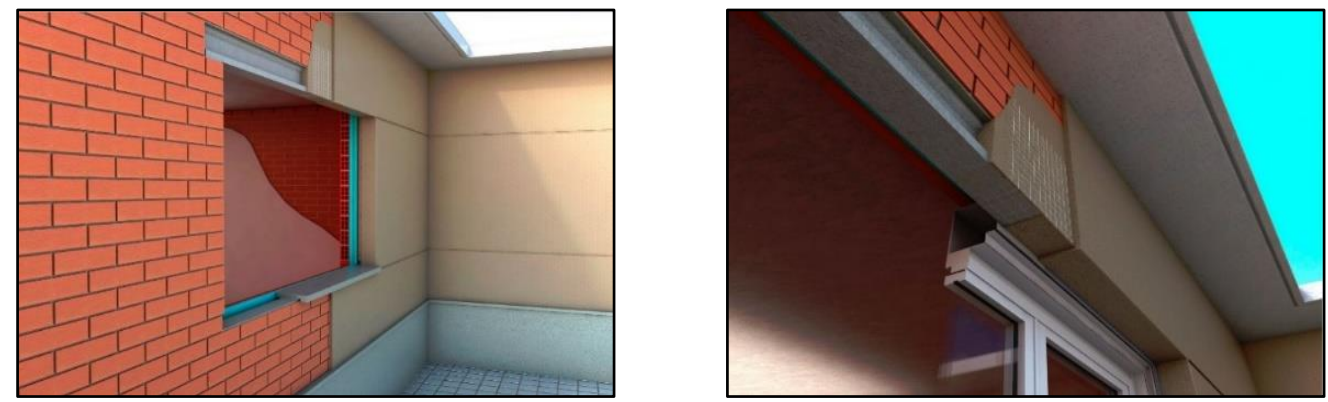

Figure 7. Examples of infographics of the singularities between facades and windows as a learning tool in university classes.

\section{Conclusions}

The current study considers a database of 1615 cases of judicial complaints filed in Spain regarding defects in windows. In the literature review that was carried out, there were no references to similar work based on this type of source data, the extension of which provides quite a complete view on the reality of the problems that users complain about in these construction units $(100 \%$ of the cases existing in Spain over 10 years).

By the analysis of said data, it can be noted that there is a clear majority of complaints related to 'water infiltrations' (dWI $=60.8 \%$ ). Far behind, as to their frequency, and with nearly identical percentages between them are the defects related to 'air permeability' ( $\mathrm{dAP}=19.4 \%)$ and 'humidity by condensation' $(\mathrm{dAP}=19.0 \%)$. As for the originating causes that lead to the defects, the 'absence/deficiency of sealant' and 'inadequate construction material and/or placement' together result in $83.4 \%$ of the cases, it being thus shown that problems are usually focused on aspects related to the placement of windows.

The influence of three climatological factors on the presence of the defects was also studied: rainfall, climate and latitude. As to the influence of the last (latitude), it is clear that there is a greater percentage in location strips situated in the Central part and North of the country $(80.75 \%$ of cases according to the sum of the \%NC values of Rows 1, 2, 3, 4, 6, 8 and 10 of Table 4). From the ranks of the concentrations of the defects analysed, three zones (A, B and C) were created/catalogued, it being noted that there is a greater recurrence in Zone A: locations with high rainfall/oceanic climate/North latitude (in which is obtained a relative frequency of $7.05 \times 10^{-5}$ ).

The results presented herein can be of great interest for researchers of other countries who wish to know the probability of judicial complaints by building users. The values that were handled are highly representative, since they correspond to the totality of cases complained about in the span of time that was indicated.

This information can also be of great assistance for reducing the impact of low-quality processes [45]. The defects and the originating causes found in this research enable the different agents participating in the construction process to possess specific and highly useful information to minimise errors in the design and execution stages [41]. This will significantly lower conflicts and will make the construction 
process more sustainable, given that there will be less litigation during the stage of the use of the buildings, and repair costs will be significantly reduced.

Author Contributions: Conceptualization, M.J.C.-A.; data curation, M.J.C.-A.; formal analysis, C.E.R.-J. and D.B.-H.; investigation, M.J.C.-A.; methodology, M.J.C.-A.; validation, J.M.; writing—original draft, M.J.C.-A. and C.E.R.-J.; writing-review and editing, D.B.-H. and J.M. All authors have read and agreed to the published version of the manuscript.

Funding: This research received no external funding.

Acknowledgments: The current work was carried out within the MUSAAT Foundation's Action Plan, which envisaged carrying out national research on anomalies in buildings [46].

Conflicts of Interest: The authors declare no conflict of interest.

\section{Nomenclature}

dWI-Water infiltration

dAP-Air permeability

dHC-Humidity by condensation

dOC-Oxidation or corrosion

ocAS-Absence/deficiency of sealant

ocIC-Inadequate construction

material and/or placement

ocTB-Existence of thermal bridges

ocIA-Incorrect assembly process
Entrance of water at weak points of a construction element leading to dripping and/or visible loss of this liquid.

Penetration of wind through a window, be it through the profiles of the frame or between these and the opening of the facade wall.

Physical phenomenon through which the environmental humidity liquefies in contact with a cold wall.

Deterioration of a metallic material due to lack of protection against electro-chemical attack.

This action was incorrectly carried out, failing to guarantee watertightness.

Characteristics of the material and/or the system of placement that were foreseen are insufficient.

Presence in a specific location of the envelope of a point with different thermal conductivity between different points due to a change in the thickness of the materials, to a lack of continuity between them or to their characteristics.

The process of fitting and joining materials is not correctly carried out.

\section{References}

1. Lopez, C.; Masters, F.J.; Bolton, S. Water penetration resistance of residential window and wall systems subjected to steady and unsteady wind loading. Build. Environ. 2011, 46, 1329-1342. [CrossRef]

2. Almeida, R.M.S.F.; Ramos, N.M.M.; Pereira, P.F. A contribution for the quantification of the influence of windows on the airtightness of Southern European buildings. Energy Build. 2017, 139, 174-185. [CrossRef]

3. Ramírez, E.; Pujols, W.C.; Casares, F.J.; Ramírez-Faz, J.; López-Luque, R. Development of a suitable synthetic projection to simultaneously study solar exposure and natural lighting in building windows. Energy Build. 2013, 65, 391-397. [CrossRef]

4. Carretero-Ayuso, M.J.; García-Sanz-Calcedo, J.; Rodríguez-Jiménez, C.E. Characterization and Appraisal of Technical Specifications in Brick Façade Projects in Spain. J. Perform. Constr. Facil. 2018, 32, 4018012. [CrossRef]

5. Intini, F.; Kühtz, S.; Milano, P.; Dassisti, M. Analysis of sustainability assessment of building windows for italian residential market: Life cycle analysis and LEED. Procedia Environ. Sci. Eng. Manag. 2015, 2, $239-247$.

6. Mills, A.; Love, P.E.; Williams, P. Defect costs in residential construction. J. Constr. Eng. Manag. 2009, 135, 12-16. [CrossRef]

7. Madureira, S.; Flores-Colen, I.; de Brito, J.; Pereira, C. Maintenance planning of facades in current buildings. Constr. Build. Mater. 2017, 147, 790-802. [CrossRef]

8. Love, P.E.D.; Smith, J.; Ackermann, F.; Irani, Z.; Teo, P. The costs of rework: Insights from construction and opportunities for learning. Prod. Plan. Control 2018, 29, 1082-1095. [CrossRef]

9. Vilutiene, T.; Ignatavičius, Č. Towards sustainable renovation: Key performance indicators for quality monitoring. Sustainability 2018, 10, 1840. [CrossRef] 
10. Van Den Bossche, N.; Janssens, A. Airtightness and watertightness of window frames: Comparison of performance and requirements. Build. Environ. 2016, 110, 129-139. [CrossRef]

11. d'Ambrosio Alfano, F.R.; Dell'Isola, M.; Ficco, G.; Palella, B.I.; Riccio, G. Experimental air-tightness analysis in mediterranean buildings after windows retrofit. Sustainability 2016, 8, 991. [CrossRef]

12. Baiburin, A.K.; Rybakov, M.M.; Vatin, N.I. Heat loss through the window frames of buildings. Mag. Civ. Eng. 2019, 85. [CrossRef]

13. Hee, W.J.; Alghoul, M.A.; Bakhtyar, B.; Elayeb, O.; Shameri, M.A.; Alrubaih, M.S.; Sopian, K. The role of window glazing on daylighting and energy saving in buildings. Renew. Sustain. Energy Rev. 2015, 42, 323-343. [CrossRef]

14. Cappelletti, F.; Gasparella, A.; Romagnoni, P.; Baggio, P. Analysis of the influence of installation thermal bridges on windows performance: The case of clay block walls. Energy Build. 2011, 43, 1435-1442. [CrossRef]

15. Kim, S.H.; Jeong, H.; Cho, S. A study on changes of window thermal performance by analysis of physical test results in Korea. Energies 2019, 12, 3822. [CrossRef]

16. Gruner, M.; Matusiak, B.S. A novel dynamic insulation system for windows. Sustainability 2018, $10,2907$. [CrossRef]

17. Koo, B.; Lee, K.; An, Y.; Lee, K. Solar heat gain reduction of ventilated double skin windows without a shading device. Sustainability 2017, 10, 64. [CrossRef]

18. Pereira, C.; de Brito, J.; Silvestre, J.D. Contribution of humidity to the degradation of façade claddings in current buildings. Eng. Fail. Anal. 2018, 90, 103-115. [CrossRef]

19. Van Den Bossche, N.; Huyghe, W.; Moens, J.; Janssens, A.; Depaepe, M. Airtightness of the window-wall interface in cavity brick walls. Energy Build. 2012, 45, 32-42. [CrossRef]

20. Park, S.; Song, S.-Y. Case study on the inspection and repair of window condensation problems in a new apartment complex. J. Perform. Constr. Facil. 2018, 32, 4018071. [CrossRef]

21. Calderón, S.; Sandoval, C.; Inzunza, E.; Cruz-Noguez, C.; Rahim, A.B.; Vargas, L. Influence of a window-type opening on the shear response of partially-grouted masonry shear walls. Eng. Struct. 2019, 201, 109783. [CrossRef]

22. Soares, N.; Martins, C.; Gonçalves, M.; Santos, P.; da Silva, L.S.; Costa, J.J. Laboratory and in-situ non-destructive methods to evaluate the thermal transmittance and behavior of walls, windows, and construction elements with innovative materials: A review. Energy Build. 2019, 182, 88-110. [CrossRef]

23. Meiss, A.; Feijó-Muñoz, J. The energy impact of infiltration: A study on buildings located in north central Spain. Energy Effic. 2015, 8, 51-64. [CrossRef]

24. Prignon, M.; Van Moeseke, G. Factors influencing airtightness and airtightness predictive models: A literature review. Energy Build. 2017, 146, 87-97. [CrossRef]

25. Bienvenido-Huertas, D.; Moyano, J.; Marín, D.; Fresco-Contreras, R. Review of in situ methods for assessing the thermal transmittance of walls. Renew. Sustain. Energy Rev. 2019, 102, 356-371. [CrossRef]

26. Lucchi, E. Applications of the infrared thermography in the energy audit of buildings: A review. Renew. Sustain. Energy Rev. 2018, 82, 3077-3090. [CrossRef]

27. Rodríguez-Jiménez, C.E.; Moyano, J.; Carretero-Ayuso, M.J.; Guillén-Lupiánez, M.I. Methodological proposal for on-site watertightness testing with wind pressure on facade windows. J. Perform. Constr. Facil. 2018, 32, 4017139. [CrossRef]

28. Santos, A.; Vicente, M.; de Brito, J.; Flores-Colen, I.; Castelo, A. Analysis of the inspection, diagnosis, and repair of external door and window frames. J. Perform. Constr. Facil. 2017, 31, 4017098. [CrossRef]

29. Siddiqui, A.; Biswas, A.P. Defects a critical issue in construction. Int. J. Sci. Technol. Res. 2019, 8, 147-150.

30. Love, P.E.D.; Edwards, D.J. Forensic project management: The underlying causes of rework in construction projects. Civ. Eng. Environ. Syst. 2004, 21, 207-228. [CrossRef]

31. Asif, M.; Muneer, T.; Kubie, J. Sustainability analysis of window frames. Build. Serv. Eng. Res. Technol. 2005, 26, 71-87. [CrossRef]

32. Carlisle, S.; Friedlander, E. The influence of durability and recycling on life cycle impacts of window frame assemblies. Int. J. Life Cycle Assess. 2016, 21, 1645-1657. [CrossRef]

33. Ferreira, C.; Silva, A.; de Brito, J.; Dias, I.S.; Flores-Colen, I. The impact of imperfect maintenance actions on the degradation of buildings' envelope components. J. Build. Eng. 2020, 33, 101571. [CrossRef]

34. Santos, A.; Vicente, M.; De Brito, J.; Flores-Colen, I.; Castelo, A. Inspection, diagnosis, and rehabilitation system of door and window frames. J. Perform. Constr. Facil. 2017, 31, 4016118. [CrossRef] 
35. Fernandes, D.; de Brito, J.; Silva, A. Methodology for service life prediction of window frames. Can. J. Civ. Eng. 2019, 46, 1010-1020. [CrossRef]

36. Maia, M.; Morais, R.; Silva, A. Application of the factor method to the service life prediction of window frames. Eng. Fail. Anal. 2020, 109, 104245. [CrossRef]

37. MUSAAT. Expert Records and Reports if Accidents in Spain. In Mútua de Aparejadores y Arquitectos Técnicos; MUSAAT: Madrid, Spain, 2017.

38. SERJUTECA. Reports and Documents on Accidents Involving Professional Civil Liability of Building Surveyors and Technical Architects in Spain. In Servicios Jurídicos Técnicos Aseguradores; SERJUTECA: Madrid, Spain, 2017.

39. AEMET. Climate and Meteorological Data of Spain. Available online: http://www.aemet.es (accessed on 1 February 2020).

40. Spainish Institute of Statistics. Population and Housing Census; Spainish Institute of Statistics: Madrid, Spain, 2019.

41. Carretero-Ayuso, M.J.; García-Sanz-Calcedo, J. Analytical study on design deficiencies in the envelope projects of healthcare buildings in spain. Sustain. Cities Soc. 2018, 42, 139-147. [CrossRef]

42. Plebankiewicz, E.; Meszek, W.; Zima, K.; Wieczorek, D. Probabilistic and fuzzy approaches for estimating the life cycle costs of buildings under conditions of exposure to risk. Sustainability 2020, 12, 226. [CrossRef]

43. Farahani, A.; Wallbaum, H.; Dalenbäck, J.-O. Cost-Optimal Maintenance and Renovation Planning in Multifamily Buildings with Annual Budget Constraints. J. Constr. Eng. Manag. 2020, 146, 4020009. [CrossRef]

44. Andújar-Montoya, M.D.; Galiano-Garrigós, A.; Echarri-Iribarren, V.; Rizo-Maestre, C. BIM-LEAN as a methodology to save execution costs in building construction-An experience under the spanish framework. Appl. Sci. 2020, 10, 1913. [CrossRef]

45. Forcada, N.; Macarulla, M.; Gangolells, M.; Casals, M.; Fuertes, A.; Roca, X. Posthandover housing defects: Sources and origins. J. Perform. Constr. Facil. 2013, 27, 756-762. [CrossRef]

46. Carretero-Ayuso, M.J.; Moreno-Cansado, A. National Statistical Analysis on Construction Pathologies; MUSAAT Foundation: Madrid, Spain, 2019.

(C) 2020 by the authors. Licensee MDPI, Basel, Switzerland. This article is an open access article distributed under the terms and conditions of the Creative Commons Attribution (CC BY) license (http://creativecommons.org/licenses/by/4.0/). 